\title{
Mortality Factors for Severe Septic States in Intensive Care Unit
}

\author{
Leye $\mathrm{PA}^{1}$, Traoré $\mathrm{MM}^{2}$, Gaye $\mathrm{I}^{1}$, Créo $\mathrm{R}^{1}$, Bah $\mathrm{MD}^{2}$, Ndiaye $\mathrm{PI}^{2}$, Fall $\mathrm{ML}^{2}$, Ndoye $\mathrm{MD}^{2}$, Diouf $\mathrm{E}^{2}$ \\ ${ }^{1}$ Department of Anesthesiology and Resuscitation, Teaching Hospital Aristide Le Dantec-Faculty of Medicine, Cheikh Anta Diop University, Senegal \\ ${ }^{2}$ Department of Anesthesiology and Resuscitation, Fann Teaching Hospital-Faculty of Medicine, Cheikh Anta Diop University, Senegal
}

Submission: January 22, 2020; Published: February 13, 2020

*Corresponding author: Papa Alassane LEYE, Anesthesiology and Resuscitation Department, Teaching Hospital Aristide Le Dantec, Dakar, Senegal

\section{Summary}

Background: Sepsis is a life-threatening organ dysfunction caused by an inappropriate host response to an infection. Severe sepsis is a source of morbidity and high mortality in intensive care. The objective of our study was to analyze mortality factors associated with severe sepsis and to describe the epidemiological, clinical and therapeutic aspects.

Patients and methods: Monocentric, observational, retrospective study from January 1st, 2015 to June 30th, 2017, concerning the mortality factors of severe sepsis in 40 adult patients in the intensive care unit at Aristide Le Dantec Teaching Hospital in Dakar.

Results: Forty-seven cases of severe sepsis were identified out of a total admission of 1242, i.e an incidence of 3.78\%. 40 files were exploited. The average age of the patients was $55.75 \pm 15.84$ years, with extremes of 21 and 86 years. The most common reasons for admission were postoperative gas-gangrene follow-up in $27.5 \%$ of patients and septic shock in $25 \%$ of patients. The most common infectious foci were cutaneous (27.5\%), peritoneal $(22.5 \%)$ and pulmonary $(17.5 \%)$. Bacteriologically, there was a predominance of Gram-negative bacilli. Prognostic factors related to mortality were admission from the start for septic shock, presence of hyperthermia at admission, duration of infection before admission, impairment of renal function, and hyperkalemia.

Conclusion: Severe sepsis is responsible for significant morbidity and mortality. In our context, the prognostic factors are essentially the duration of the infection, the state of shock and the severe renal failure.

Keywords: Severe sepsis; Mortality factors; Intensive care unit

\section{Introduction}

Sepsis is a life-threatening organ dysfunction caused by an inappropriate host response to an infection. There is no more distinction between sepsis and severe sepsis [1]. Severe sepsis is a major source of morbidity and mortality in intensive care units. The objectives of our study were to analyze mortality factors related to severe sepsis received in intensive care, epidemiological and therapeutic aspects.

\section{Patients and Methods}

This is a monocentric, observational and retrospective study from January 1st, 2015 to June 30th, 2017, dealing with mortality factors for severe sepsis in the multipurpose resuscitation department at Aristide Le Dantec Teaching Hospital in Dakar. Were included all adult patients who died from severe sepsis whose records were complete. The data was collected from the records and the register of the resuscitation unit.
The studied parameters concerned:

a) Sociodemographic and anamnestic data: age, sex, time of care if diagnosed before admission, reason for hospitalization, number of patients hospitalized during the period;

b) Clinical data: signs of sepsis and septic shock, signs of organ failure, infectious focus;

c) Microbiological data;

d) Therapeutic data: vascular filling modalities, vasopressor amines used, probabilistic and adapted antibiotherapy, supportive therapies (corticosteroids, insulin therapy, mechanical ventilation, extrarenal treatment ...);

e) Evolving data: duration of infection, length of stay, mortality factors and causes of death.

The collected data were captured and analyzed with the Sphinx version 2 software. 
The descriptive study was carried out by calculating frequencies, proportions with confidence intervals for qualitative and quantitative variables, and by calculating averages with their standard deviation.

The analytical study was done with the crossed tables. The $\mathrm{p}$ value below 0.05 was considered statistically significant.

\section{Results}

During the study period, out of 1242 admitted, 47 patients died from complications of severe sepsis, i.e an incidence of $3.78 \%$. Forty files could be exploited. The average age of patients was 55.75 years, with extremes of 21 and 86 years. The sex-ratio was $0.9 \%(19 \mathrm{M} / 21 \mathrm{~F})$. Diabetes (32.5\%) was the most common site in our patients. Postoperative follow-up was the most common reason for hospitalization with $45 \%$ (27.5\% related to gas gangrene and $17.5 \%$ related to peritonitis), followed by septic shock accounted for $25 \%$. The most common infectious focus was cutaneous in 16 patients (40\%), followed by peritoneal foci in 9 patients $(22.5 \%)$ and pulmonary patients in 8 patients $(17.5 \%)$. Bacteriological findings were positive in 14 patients with a predominance of gram-negative bacillus. Vascular filling was performed in all patients on admission with crystalloids alone in $87.5 \%$ of the patients and associated with the colloids for the rest The most used vasopressor was norepinephrine in the majority of patients (29 cases), i.e $72.5 \%$. All patients received antibiotic therapy, probabilistic in $80 \%$ (32 patients) and adapted in only $20 \%$ of cases ( 8 patients). The supportive treatments and various treatments given to our patients are summarized in the table below (Table 1)

Table 1: Overall representativeness of each of the therapies established in relation to the overall population.

\begin{tabular}{|c|c|c|}
\hline Treatment & Number (n) & Percentage (\%) \\
\hline Dialysis & 2 & 5 \\
\hline Corticotherapy & 6 & 15 \\
\hline Insulin therapy & 14 & 35 \\
\hline Mechanical ventilation & 22 & 55 \\
\hline Preventive anticoagulation & 27 & 67,5 \\
\hline Vasopressives amines & 34 & 85 \\
\hline Antibiotics & 40 & 100 \\
\hline
\end{tabular}

For evolution data, the causes of death are listed in Table 2.

Table 2: Distribution of patients according to the causes of death.

\begin{tabular}{|c|c|c|}
\hline Causes of Death & Number (n) & Percentage (\%) \\
\hline Cardiovascular causes & 2 & 5 \\
\hline Neurological causes & 4 & 10 \\
\hline Respiratory causes (ARDS) & 7 & 17,5 \\
\hline Renal causes & 8 & 20 \\
\hline Mutiple organ Failure & 19 & 47,5 \\
\hline
\end{tabular}

\section{ARDS: acute respiratory distress syndrome}

The average length of stay of our patients was 6.13 days with extremes ranging from 1 to 55 days. The analytical study showed that: septic shock was an early mortality factor with a significant $p$ value at 0.024 . But there was no correlation between early mortality and other reasons for hospitalization. There was a relationship between mortality and hyperthermia $(p=0.038)$, duration of infection before admission ( $\mathrm{p}=0.007)$, impairment of renal function $(\mathrm{p}=0.019)$, and hyperkalemia with $\mathrm{p}$ significant at 0.017 .

\section{Discussion}

The epidemiology of severe septic syndromes in intensive care is now well known, as are their implications for morbidity and management difficulties. The incidence of severe sepsis is 3.78\% in our study. In France, the "Episepsis" survey, conducted in 2001 in a large number of intensive care units, showed that about $15 \%$ of patients hospitalized in intensive care, had a severe septic syndrome [2]. It is accepted that the risk of developing a severe infection increases significantly from the age of 60 , so that septic shock can be seen at any age, but it is particularly common in the elderly [3]. In our study, the average age was 55.75 years, confirming data from the literature that states a link between mortality and age in septic shock. With regard to gender, the analysis of published data does not find a causal link between sex and mortality [4]. Diabetes was the main field found in our patients. This high frequency could be explained by the delay in patient management and is thought to be responsible for the higher number of admissions for gas gangrene. This delay in management was also reflected in the frequent occurrence of septic shock at admission with a significant relationship with mortality, as well as the duration of infection before admission. The presence of hyperthermia at admission was also correlated with the occurrence of death. Other mortality factors noted in our study were acute renal failure and hyperkalemia. In the SOAP study conducted in Europe on septic patients at resuscitation department, the frequency of acute renal failure was 36\%, occurring in $72 \%$ of cases during the first 2 days of hospitalization. The overall mortality at day 60 was $35.7 \%$, with an increase depending on the severity of the acute renal failure: $36 \%$ in forms without extrarenal treatment, $41 \%$ if need of extrarenal treatment and $52 \%$ in case of anuria [5]. There is consensus among experts that prompt extrarenal treatment should be instituted in the following life-threatening situations: hyperkalemia, lysis syndrome, acute pulmonary edema, metabolic acidosis [6,7]. In our series, 29 patients had acute renal failure with only 2 patients under extrarenal treatment, and a statistically significant value was found at $\mathrm{p}=0.019$ with mortality. Therapeutically, only $20 \%$ of the patients were able to benefit from an adapted antibiotherapy 
whereas all the patients had had an initial infectious assessment as soon as admitted. This is due to the long delay in receiving results, which poses a real problem in adapting antibiotic therapy to bacteriological results. However, early and adapted antibiotic therapy is imperative and guarantees better progression during severe sepsis [8]. Inadequate initial antibiotherapy is a source of delay in treatment, lengthening the duration of stay and significant excess mortality $[9,10]$.

Supportive therapies are of great importance in the management of severe sepsis, aiming at the same time at improving the state of health of the patient, but above all at preventing the deleterious complications that may occur during the stay in intensive care; whose lethal potential would only worsen the state of these patients with already poor prognosis. With this in mind, the study on the Sepsis Survival Campaign conducted in 2012 also defined a number of recommendations to be applied in order to put the maximum potential for the patient's survival, but also to improve their end of life where appropriate [8]. A number of factors may be intimately associated with poor prognosis in septic shock. A detailed analysis of the prognostic factors associated with infections and septic states was carried out in the European "Euro sepsis" survey. The variables remaining significantly associated with death are of three types: chronic associated pathologies, the importance of physiological alterations and organ dysfunctions and the characteristics of the infection [11]. Among organ failures, renal (77\%), cardiovascular (44\%) and hematological (15\%) failures dominate the prognosis. Among the characteristics of infection, those acquired in the hospital (34\%) and in intensive care (21\%) are associated with a higher risk of death, as well as intra-abdominal infections (15\%) and those of indeterminate origin (2\%); infections with strict aerobic germs $(20 \%)$ and yeasts (12\%) are also associated with an increased risk of death, unlike Enterobacteriaceae (35\%), associated with a comparatively more favorable prognosis. In the same French multi-centric study, mechanical ventilation was the prognostic factor associated with the highest mortality rate [12]. In our study, we had 20\% renal failure and 55\% ventilated patients. In our series, the prognostic factors of mortality in univariate analysis approached this study by several parameters: demographic (age, direct admission to intensive care, severity of the disease: acute respiratory insufficiency, acute respiratory distress syndrome ARDS, acute renal failure) and therapeutic interventions: mechanical ventilation, use of vasopressive amines.

\section{Conclusion}

Severe sepsis is associated with significant morbidity and mortality. In our context, the prognostic factors are essentially the duration of the infection, the state of shock and the severe renal failure. The prognosis can be improved thanks to the early and effective management of identified mortality factors.

\section{References}

1. Singer M, Deutschman CS, Seymour CW, Shankar-Hari M, Annane D, et al. (2016) The third international consensus definitions for sepsis and septic shock (sepsis-3). JAMA 315(8): 801-810.

2. Brun-Buisson C, Meshaka P, Pinton P, Vallet B (2004) Episepsis: a reappraisal of the epidemiology and outcome of severe sepsis in French intensive care units. Intensive Care Med 30(4): 580-588.

3. Angus DC, Linde-Zwirble WT, Lidicker J, Clermont G, Carcillo J, et al. (2001) Epidemiology of severe sepsis in the United States: analysis of incidence, outcome, and associated costs of care. Crit Care Med 29(7): 1303-1310.

4. Brun-Buisson C, Doyon F, Carlet J, Dellamonica P, Gouin F et al. (1995) Incidence, Risk Factors, and Outcome of Severe Sepsis and Septic Shock in Adults. JAMA 274(12): 968-974.

5. Payen D, de Pont AC, Sakr Y, Spies C, Reinhart K, et al. (2008) A positive fluid balance is associated with a worse outcome in patients with acute renal failure. Crit Care 12(3): 74.

6. Vinsonneau C, Allain-Launay E, Blayau C, Darmon M, Ducheyron D, et al. (2015) Renal replacement therapy in adult and pediatric intensive care: recommendations by an expert panel from the French Intensive Care Society (SRLF) with the French Society of Anesthesia Intensive Care (Sfar) French Group for Pediatric Intensive Care Emergencies (GFRUP) the French Dialysis Society (SFD). Ann Intensive Care 5(1): 58.

7. Kellum JA, Lameire N, Aspelin P, Barsoum RS, Burdmann, et al. (2012) Acute Kidney Injury Work Group, Improving Global Outcomes (KDIGO), KDIGO Clinical Practice Guideline for Acute Kidney Injury. Kidney International Supplements 2(1): 1-138.

8. Dellinger RP, Levy MM, Rhodes A, Annane D et al. (2013) Campagne Surviving Speechs (Survivre au sepsis): Guide international pour la prise en charge du sepsis sévère et du choc septique-2012. Crit Care Med 41(2).

9. Paul M, Shavi V, Muchtar E, Kaviv G, Robenshtok E, et al. (2010) Systematic review and meta-analysis of the efficacy of appropriate empiric antibiotic therapy for sepsis. Antimicrob Agents Chemother 54(11): 4851-4863.

10. Garnacho-Montero J, Ortiz-Leyba C, Herera-Melero I, Aldabo-Pallas T, Cayuela-Lominguez A, et al. (2008) Mortality and morbidity attribuable to inadequate empirical antimicrobial therapy in patients admitted to the ICU with sepsis : a matched cohort study. J Antimicrob Chemother 61(2): 436-441.

11. Brun-Buisson C (2006) Épidémiologie des états septiques graves. Presse Med 35: 513-520

12. Annane D, Aegerter P, Jars-Guincestre MC, Guidet B (2003) Current epidemiology of septic shock. Crit Care Med 168: 165-172. 
This work is licensed under Creative Commons Attribution 4.0 License

DOI: 10.19080/JAICM.2020.10.555787
Your next submission with Juniper Publishers will reach you the below assets

- Quality Editorial service

- Swift Peer Review

- Reprints availability

- E-prints Service

- Manuscript Podcast for convenient understanding

- Global attainment for your research

- Manuscript accessibility in different formats ( Pdf, E-pub, Full Text, Audio)

- Unceasing customer service

Track the below URL for one-step submission https://juniperpublishers.com/online-submission.php 